\title{
A Psychocutaneous Profile of Psoriasis Patients Who Are Stress Reactors A Study of 127 Patients
}

\author{
Madhulika A. Gupta, M.D., F.R.C.P.(C), Aditya K. Gupta, M.D., \\ F.R.C.P.(C), Sueann Kirkby, B.S.N., Nicholas J. Schork, B.S., \\ Susan K. Gorr, B.A., Charles N. Ellis, M.D., and John J. Voorhees, M.D.
}

\begin{abstract}
Psoriasis is a chronic, relapsing, cutaneous condition with a $1 \%-2 \%$ prevalence in the general population. About $40 \%$ of psoriatics report that psychosocial stress significantly exacerbates their condition. However, the clinical characteristics of the subgroup of psoriatic patients who are stress reactors have not been delineated. At a practical clinical level it is therefore difficult to implement specific psychosocial treatments among the psoriatic population. In this study, we compared the psychocutaneous characteristics of patients who reported that stress exacerbated their psoriasis, i.e., the high stress reactors $(\mathrm{N}=64)$ to the subgroup who reported no significant association between stress and their psoriasis, i.e., the low stress reactors $(\mathrm{N}=63)$. The high stress reactors had more disfiguring disease clinically $(\mathrm{p}<0.02)$; psychologically they tended to rely more upon the approval of others $(\mathrm{p}<0.05)$ and experienced more psoriasis-related daily stress $(\mathrm{p}<0.005)$. The high stress reactors also reported more flare-ups of their psoriasis during the 6 months prior to admission ( $\mathrm{p}<0.05$ ). We have shown that the high stress reactors can be clinically delineated from the low stress reactors. Certain psychosocial interventions will most likely decrease the morbidity associated with psoriasis among the high stress reactors, and may possibly even result in a decline in the number of major flare-ups of the psoriasis.
\end{abstract}

Psoriasis is a chronic, relapsing, cutaneous condition with a $1 \%-2 \%$ prevalence in the general population [1]. The characteristic lesions of psoriasis are erythematous, thickly scaling plaques that may affect any region of the skin [1]. Psychosocial stress

From the Departments of Psychiatry (M.A.G.; N.J.S.; S.K.G.) and Dermatology (A.D.G.; S.A.K.; C.N.E.; J.J.V.), University of Michigan Medical Center, Ann Arbor.

Address reprint requests to: M. A. Gupta, M.D., Department of Psychiatry, University of Michigan Medical Center, 1500 E. Medical Center Drive, Box 0704, Ann Arbor, MI 48109.

166

ISSN 0163-8343/89/\$3.50 has been reported to play an important role in the onset or exacerbation of psoriasis [2-17] in approximately $40 \%$ [1-4] of cases. Some studies have even reported that up to $80 \%$ of psoriatics are stress reactors $[6,17]$. Only a few authors have questioned the association between stress and psoriasis $[18,19]$. However, in spite of this relatively large body of literature there exist no specific guidelines that help delineate the potential "stress reactor" clinically. Various psychosocial interventions have been reported to be an important adjunct in the overall management of psoriasis $[9,10,14,15,20$ 30]. However, at a clinical level, it is often not practical to implement such interventions if the potential stress reactors are not identified.

The various studies on stress and psoriasis have employed three major dimensions of psychosocial stress: (1) major life events [3-7,16,18], (2) psychologic or personality factors $[3,4,6,7,16,17,20]$, and (3) social support $[16,18]$. A few studies have also included some aspects of disease-related stress $[4,16]$ among their stress measures. There is a relative lack of objective clinical dermatologic data in the existing studies $[2,7,16,17,18,31,32,33]$, making it difficult to evaluate the effect of disease severity or cosmetic disfigurement on the "stress reactivity" of the patient.

In this study we have delineated some psychocutaneous features that clinically distinguish the subgroup of patients with psoriasis whose disease was reported to be exacerbated by stress to a significant degree, i.e., the high stress reactors, to the subgroup who did not report a significant association between stress and their psoriasis, i.e., the

General Hospital Psychiatry 11, 166-173, 1989 (C) 1989 Elsevier Science Publishing Co., Inc 655Avenue of the Americas, New York, NY 10010 
low stress reactors. We have considered all the three major dimensions of stress used in most of the previous studies along with indices of psoriasisrelated stress. The purpose of this study is to clinically distinguish the relatively large subgroup of patients with psoriasis in whose case psychosocial interventions will most likely prove to be a useful adjunct to the conventional therapies for the psoriasis.

\section{Patients and Methods}

This is part of a large study evaluating a wide range of psychosocial parameters among patients with psoriasis that is currently being carried out as a collaborative effort between the Departments of Psychiatry and Dermatology at the University of Michigan.

To date, we have studied 127 consecutive consenting patients with mainly plaque psoriasis admitted to the Dermatology inpatient unit. All patients received a standard course of treatment

Figure 1. Distribution of patient ( $n=127)$ self-ratings of the statement "Stressful situations frequently make my psoriasis worse." A 10-point rating scale was used, where 1 denoted "not at all" and 10 denoted "very markedly." The median rating of 7 was used as the cutoff that delineated the high (ratings of 7-10) and low (ratings of 1-6) stress reactors. consisting of topical corticosteroids, anthralin, tar, and ultraviolet B (UVB) phototherapy. Both the psychosocial and dermatologic ratings were obtained within the first week of admission to the Dermatology Unit. General clinical and demographic data were obtained from all patients.

\section{Measure of "Stress Reactivity"}

Since "stress" is a primarily subjective symptom, the patients were asked to self-rate the extent to which stressful situations made their psoriasis worse on a 10-point scale at the time of admission. They responded to the following statement: "Stressful situations frequently make my psoriasis worse," and the 10-point scale consisted of a line with 10 equal sections. Each of the sections were labeled numerically, with 1 denoting "not at all" and 10 denoting "very markedly." The subjects were asked to circle the number that best applied to their condition.

\section{Delineation of High vs. Low Stress Reactors}

As the stress reactance scale described above is our own measure and not yet tested outside this study, we chose the self-rated stress score that was closest to the median as the cutoff point for high and low stress reactance. The $50 \%$ cutoff was chosen because between $40 \%[2-5]$ and $80 \%[6,17]$ of

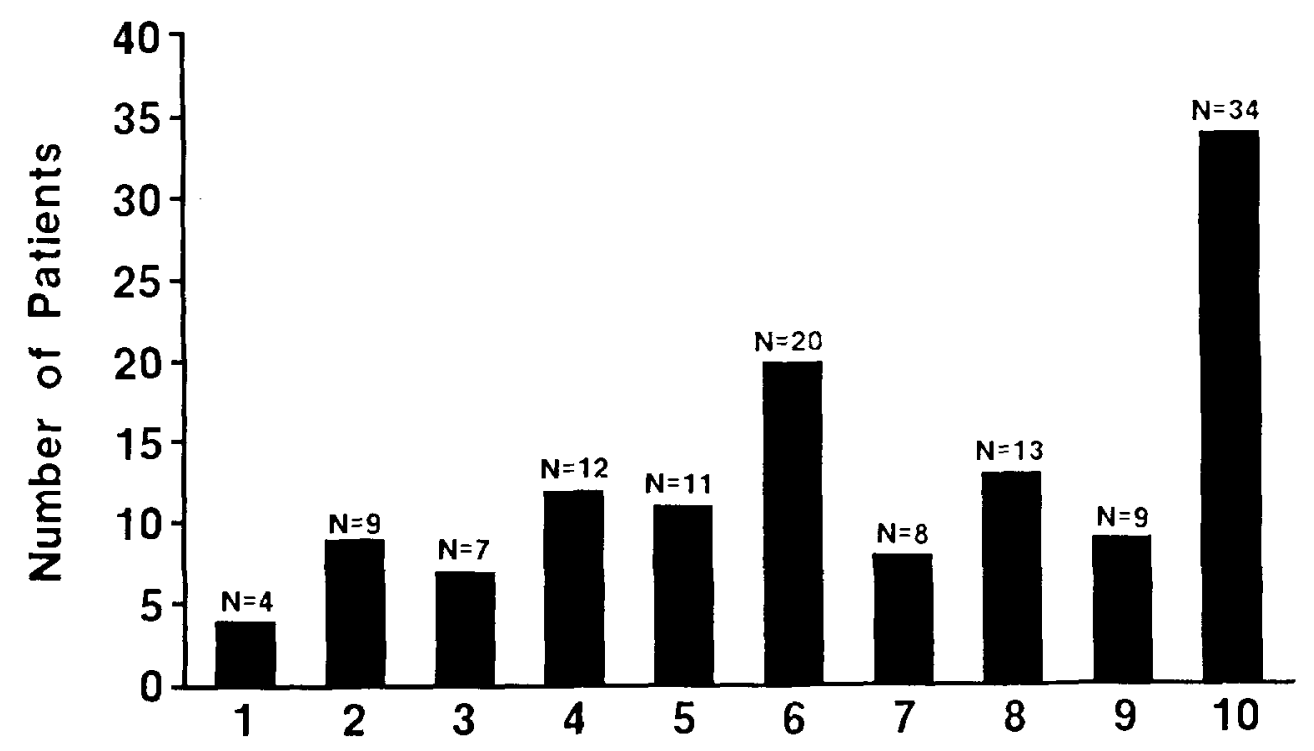

\section{Patient Self-rating of Stress Reactivity of Psoriasis}


Table 1. Summary of the stress and dermatologic measures

Psychosocial stress measures

1. Major Life Events 6 Months Prior to Admission Social Readjustment Rating Scale (SRRS) [35]

2. Psychological Measures

a. Symptom Checklist, Revised Version (SCL-90R) [36]

b. Speilberger State-Trait Personality Inventory (STPI) [37]

c. Carroll Rating Scale for Depression (CRSD) [38, 39]

d. Interpersonal Dependency Inventory Subscale (IDS) [40]

e. Rosenberg's Self-Esteem Questionnaire [41,42]

3. Social Support

Index of Social Support [43-45]

4. Minor Daily Life Events and Psoriasis Related Daily Stress $^{a}$

a. Hassles Scale

b. Psoriasis Life Stress Inventory (PLSI) ( 3 measures)

Number of Minor Daily Life Events 1 month prior to admission (PLSI 1)

Total Stress Associated with the events (PLSI 2)

Psoriasis-Related Daily Stress (PLSI 3)

Dermatologic measures

1. Percentage of total body surface area affected by psoriasis [46]

2. Total severity of psoriasis affecting all body regions (degree of scaling, erythema and plaque thickness).

3. Severity of psoriasis affecting the "emotionally charged" body regions (i.e., scalp, face, neck, forearms, hands, and genital region).

${ }^{a}$ M.A. Gupta's own rating scales. Manuscript in preparation for the Psoriasis Life Stress Inventory (PLSI).

patients with psoriasis have been reported to be stress reactors, and we therefore felt that the 50\% cutoff point was reasonable. Figure 1 shows the distribution of stress ratings among our $127 \mathrm{pa-}$ tients. Since a rating of 7 was closest to the median, subjects with self-ratings of 7 or higher were categorized as "high stress reactors" and those with ratings of 1 to 6 as "low stress reactors."

\section{General Clinical and Demographic Measures}

The following general clinical and demographic measures were obtained for each patient: number of flare-ups of psoriasis over the 6 months prior to admission, age at onset and duration of psoriasis, age, weight, and height at the time of admission, average reported daily alcohol consumption (converted to grams of ethanol consumed) during the 6 months prior to admission, sex, marital status, employment status, and income.

\section{Psychosocial Stress Measures}

Four major areas related to psychosocial stress were evaluated (Table 1): (1) major life events, (2) psychologic or personality factors, (3) social support, and (4) minor daily stressful events or hassles, including psoriasis-related daily stress. All the psychosocial measures were self-ratings. The patients were identified by a code number only on the questionnaires, and their anonymity was maintained at all times.

Major Life Events. A modified version [34] of the Social Readjustment Rating Scale (SRRS), a life events inventory adapted from Holmes and Rahe [35], was used. This measured stress from major life events during the 6 months prior to the study.

Psychologic Measures. (1) The Symptom Checklist, Revised Version (SCL-90R) [36], a 90item instrument that measures 9 symptom dimensions, including somatization, obsessive-compulsiveness, interpersonal sensitivity, depression, anxiety, hostility, phobic anxiety, paranoid ideation, and psychoticism.

(2) The Spielberger State-Trait Personality Inventory (STPI) [37], two 30-item instruments each measuring state and trait anger, anxiety and curiosity, respectively.

(3) The Carroll Rating Scale for Depression (CRSD) [38,39], a 52-item instrument used in the screening for clinical depression.

(4) One subscale of the Interpersonal Dependency Inventory (IDS) [40], an 18-item subscale of a 48-item instrument measuring the degree of emotional reliance on another person. This subscale generally measures the extent to which a person relies upon the approval of others.

(5) Rosenberg's Self-Esteem Questionnaire $[41,42]$, a ten-item instrument used as a measure of self-esteem.

Social Support. The Index of Social Support [43] was adapted from an instrument developed by Kaplan et al. [44]. The adapted index consists of 7 sets of vignettes from the original 16 [44]. Each set of vignettes consists of three scenarios describing individuals who have variable levels of social sup- 
port [45]. The patients identified themselves with the scenarios that they believed best described their situation.

Minor Daily Stressful Events and PsoriasisRelated Daily Stress. We were unable to find any previously validated instruments that measured psoriasis-related daily stress. We therefore developed our own instruments, which are described below.

(1) The Hassles Scale, a 10-point scale that reads as follows: "I have to deal with a lot of day-today hassles that others don't have to face because of my psoriasis." The patients self-rated the extent to which they had to face day-to-day stresses because of their psoriasis, with a rating of 1 denoting "not at all" and a rating of 10 denoting "very markedly."

(2) The Psoriasis Life Stress Inventory $(P L S I)^{1}$ a $41-$ item instrument designed to measure stress resulting from the impact of psoriasis upon the quality of life. This is a list of daily events that may be related to the psoriasis. Although we have no prevalidated instruments to compare with the PLSI, our psychometric analyses have confirmed the validity of our instrument to a degree. Factor analysis involving the 41 items suggests that one 18 -item factor underlies the 41 items as a whole. This factor consists of items such as people making insensitive remarks about the patient's appearance, having to avoid clothes that expose certain body regions, having to avoid certain public places and social situations, and so on. The instrument has three subscales and patients were asked to indicate (1) which of a list of events had occurred 1 month prior to admission (PLSI 1), and (2) using a 4-point scale they were also asked to rate the degree of stress associated with the event (PLSI 2), and (3) using the same 4-point scale rate the extent to which they believed that psoriasis was responsible for the stress (PLSI 3). General stress scores associated with the daily stressful events (PLSI 2) and a psoriasis-related daily stress score (PLSI 3) were obtained for each patient by adding up the respective stress ratings.

\section{Clinical Dermatologic Ratings}

The dermatologic ratings that were carried out within the first week of admission included the percentage of total body surface area affected by psoriasis [46] and the severity of psoriasis affecting

\footnotetext{
${ }^{1}$ Gupta M. A.: Manuscript in preparation.
}

each body region using a 10-point scale (from this a total severity score was calculated, by adding each severity rating and dividing it by the total number of body regions affected). The psoriasis severity ratings took into account the degree of erythema, scaling, and plaque thickness. The clinicians were unaware of the psychosocial self-ratings of the patients.

\section{Statistical Analysis}

Stepwise discriminant function analysis [47] was used to determine which variables were independently and significantly different between the two groups, and therefore best characterized the high and low stress reactor groups. Stepwise multiple regression analysis [47] was used to assess the relative contribution of the psychosocial measures towards the various indices of psoriasis severity. In order to better isolate the severity of the psoriasis affecting individual body regions, in the context of overall psoriasis severity, the residuals obtained after regressing the individual body region severity score on the total body severity score were used. The residuals represent the variation in the severity of psoriasis in the individual body regions not explained by total or overall body psoriasis severity. Simple group differences were assessed by the Student's two-sample $t$-test for continuous data and the chi-square test for discrete data.

\section{Results}

\section{General Clinical and Demographic Findings}

The high stress reactors (mean \pm SEM age: $45 \pm$ 1.7 years) were younger than the low stress reactors (mean \pm SEM age: $51 \pm 2.1$ years) $(p<0.05)$. Other features, such as the mean duration of psoriasis, did not distinguish the high stress reactors (mean duration $\pm \mathrm{SEM}: 19 \pm 1.6$ years) from the low stress reactors (mean duration \pm SEM: $20 \pm$ 2 years).

\section{Psychosocial Stress Measures That Differentiated Between the High and Low Stress Reactor Groups}

Stepwise discriminant function analysis using all the stress measures (Table 1) revealed that the high stress reactors experienced more disease-related stress in comparision to the low stress reactors, as evidenced by both higher hassles rating (Hassles scale) $(p<0.05)$ and higher psoriasis-related stress 
M. A. Gupta et al.

Table 2. Psychosocial stress and dermatologic measures that discriminated the high and low stress reactor psoriatic patients

Findings at admission

Psychosocial Stress ${ }^{a}$

High stress reactors had higher ratings on the following:

1. Interpersonal Dependency Inventory Subscale (IDS) [40] $(p<0.05)$

2. “Hassles" score (Hassles Scale) $(p<0.05)$

3. Psoriasis-Related Daily Stress (PLSI 3) $(p<0.005)$

Dermatologic ${ }^{a}$

High stress reactors had more severe psoriasis in their "emotionally charged" body regions (i.e., scalp, face, neck, forearms, hands, and genital region) $(p<0.02)$.

${ }^{a}$ Stepwise discriminant function analysis [47] using all stress or dermatologic measures listed in Table 1.

(PLSI 3) $(p<0.005)$ among the high stress reactors (Table 2). Psychologically, the high stress reactors were more interpersonally dependent or tended to rely more upon the approval of others (IDS) $(p<$ 0.05) (Table 2).

\section{Dermatologic Findings That Differentiated Between the High and Low Stress Reactors}

Stepwise discriminant function analysis using all the dermatologic measures (Table 1) revealed that the high stress reactors had greater psoriasis severity $(p<0.02)$ on their scalp, face, neck, forearms, hands, and genital region. We labeled these body regions as "emotionally charged," as psoriasis in these regions is more likely to arouse emotional reactions in the patient, because of its effect upon the patient's appearance and sexuality (Table 2 ). The high and low stress reactors did not differ with respect to the usual dermatologic criteria of psoriasis severity, such as the percentage of total body surface area affected, or overall severity measured by the degree of plaque thickness, scaling, and erythema. In a retrospective survey, the high stress reactors also reported a greater number of flare-ups of their psoriasis during the 6 months prior to admission $(p<0.05)$.

\section{Relation Between the Stress Measures and the Individual Dermatologic Measures Among the High Stress Reactors}

Stepwise multiple regression analysis of all the stress measures (Table 1) on the individual der-
Table 3. Relation ${ }^{a}$ between the dermatologic and all stress measures among the high and low stress reactors

\begin{tabular}{|c|c|c|}
\hline \multirow{3}{*}{$\begin{array}{l}\text { Dermatologic } \\
\text { measure }\end{array}$} & \multicolumn{2}{|c|}{$\begin{array}{l}\text { Stress variable(s) in the regression } \\
\text { equation }\end{array}$} \\
\hline & $\begin{array}{l}\text { High stress } \\
\text { reactors }\end{array}$ & $\begin{array}{l}\text { Low stress } \\
\text { reactors }\end{array}$ \\
\hline & $(N=64)$ & $(N=63)$ \\
\hline $\begin{array}{l}\text { 1. Percentage of } \\
\text { total body } \\
\text { surface area } \\
\text { affected by } \\
\text { psoriasis }\end{array}$ & $\begin{array}{l}\text { IDS }(r=0.35 \\
p<0.05)\end{array}$ & No variables \\
\hline $\begin{array}{l}\text { 2. Total severity of } \\
\text { psoriasis } \\
\text { affecting all } \\
\text { body regions }\end{array}$ & $\begin{array}{l}\text { IDS }(r=0.32 \\
\quad p<0.05)\end{array}$ & $\begin{array}{l}\text { State anger } \\
(\text { STPI) } \\
(r=0.40 \\
p<0.005)\end{array}$ \\
\hline $\begin{array}{l}\text { 3. Severity of } \\
\text { psoriasis } \\
\text { affecting } \\
\text { "emotionally } \\
\text { charged" body } \\
\text { regions }\end{array}$ & $\begin{array}{l}\text { Hassle score } \\
\text { (Hassles scale) } \\
(r=0.35 \\
p<0.05)\end{array}$ & $\begin{array}{l}\text { PLSI } 1(r=0.40 \\
\quad p<0.01)\end{array}$ \\
\hline
\end{tabular}

${ }^{a}$ Stepwise multiple regression analysis [47] using all stress variables listed in Table 1.

matologic measures revealed the following: the disease-related stress score (Hassles score) correlated directly with the severity of psoriasis in the "emotionally charged" body regions $(r=0.35, p<0.05)$ (Table 3). Interpersonal dependency or tendency of the patient to rely upon the approval of others (IDS) correlated directly with indices of disease severity, such as the percentage of total body surface area affected $(r=0.35, p<0.05)$ and the overall severity of psoriasis $(r=0.32, p<0.05)$ (Table 3). The Hassles score (Hassles scale) also correlated directly with the reported number of flare-ups of psoriasis during the 6 months prior to admission $(r=0.29, p<0.05)$.

\section{Relation Between the Stress Measures and the Individual Dermatologic Measures Among the Low Stress Reactors}

Stepwise multiple regression analysis of all the stress measures (Table 1) on the individual dermatologic measures revealed the following: the intensity of anger the patient was experiencing at the 
time of the study (state anger, STPI), correlated directly with the total severity of psoriasis $(r=$ $0.40, p<0.005$ ). The number of minor daily events (PLSI 1) correlated directly with the severity of psoriasis in the emotionally charged body regions $(r=0.40, p<0.01)$.

\section{Discussion}

We have identified some psychocutaneous characteristics that clinically distinguish psoriatics who report that stress exacerbates their disease (i.c., the high stress reactors) from the psoriatics who do not report a significant association between stress and their psoriasis (i.e., the low stressor reactors). The high stress reactors (1) had more disfiguring disease clinically as evidenced by greater psoriasis severity in their "emotionally charged" body regions, however, did not have greater psoriasis severity overall (Table 2); (2) psychologically, were more interpersonally dependent (IDS) or tended to rely more upon the approval of others (Table 2) and, unlike the low stress reactors, did not report anger in association with their disease (Table 3); and (3) reported more disease-related stress in contrast to stress from major life events (Table 2).

Among the high stress reactors, the disease-related stress score (Hassles score) correlated directly with psoriasis severity in the "emotionally charged" body regions (Table 3), which is consistent with our observation that the cosmetic disfigurement and social stigma of psoriasis significantly contribute toward the psoriasis-related stress. High stress reactivity is partly secondary to the greater cosmetic disfigurement among the high stress reactors. A relatively large percentage of psoriatics have lesions in their "cmotionally charged" body regions at some point during the course of their illness, as psoriasis affects the face in $33 \%$ of patients, upper extremities in $46 \%$, and the external genitalia among $19 \%$ of males and $11 \%$ of female patients at some time during the course of their disease [2]. This suggests that a relatively large number of patients with psoriasis are potentially vulnerable to the stresses resulting from the impact of psoriasis upon appearance and sexuality.

The degree of interpersonal dependency (IDS) correlated directly with indices of psoriasis severity (Table 3) which suggests that the high stress reactors feared greater social disapproval as their psoriasis worsened. This feeling of social disapproval is most likely an important basis for the disease- related stress. Furthermore, the tendency of the high stress reactors to withhold angry feelings in the face of social disapproval, and greater cosmetic disfigurement probably impedes their capacity to cope with the chronic disease-related stresses. The younger age of the high stress reactors probably indicates that these patients, who were at a life stage when societal norms require that they function at a high level both socially and occupationally, found the cosmetic disfigurement to be a greater impediment and therefore more stressful. Fiftyeight percent of psoriatics develop their condition before age 30 years and $35 \%$ before age 20 years [48], suggesting that the cosmetic disfigurement affects a significant number of patients at a developmental stage when they may be the most selfconscious about their appearance.

It appears that the chronic, low-grade, and sometimes unremitting stress, such as the psoriasis-related stress, plays a more important role than the generally acute, severe, and relatively short-lived stress resulting from major life events [49]. This may be a basis for the varying and sometimes conflicting conclusions regarding the relation between stress and psoriasis [18], as most studies have used major life events as a measure of psychosocial stress. Among our patients, the diseaserelated stress was also associated with more flareups of psoriasis. More frequent flare-ups of the psoriasis may have contributed towards greater disease-related stress among the high stress reactors. Alternately, it is possible that in some cases, chronic psoriasis-related psychosocial stress results in certain yet unknown psychophysiologic reactions that in turn exacerbate the skin condition.

Our study has delineated certain distinct psychologic coping mechanisms rather than well-defined psychiatric syndromes (e.g., depressive illness) that distinguish the high stress reactors from the low stress reactors. In contrast to the high stress reactors, who feared social disapproval, the low stress reactors asserted angry feelings in reaction to disease severity (Table 3 ). The low stress reactors, like the high stress reactors, face minor daily life events in relation to psoriasis in their "emotionally charged" body regions (PLSI 1) (Table 3). This finding underlies the negative reactions of the public towards patients with psoriasis. This is exemplified by a recent survey by the National Psoriasis Foundation that reported that $50 \%$ of psoriatics were bothered by the fact that they had to conceal their lesions from others [50]. However, 
unlike the high stress reactors, the low stress reactors did not report more stress in relation to these events (e.g., higher PLSI 3 scores or higher Hassles scores) (Table 3 ). This is probably related to their ability to assert anger more effectively, and also to the fact that they tended to have less cosmetically disfiguring disease.

When assessing a patient with psoriasis, the clinician should specifically inquire whether the patient's psoriasis is stress reactive. This is important, as the high stress reactors not only appear to experience more psychologic morbidity but may also experience more frequent exacerbations of their disease. Our study suggests that the high stress reactors are more likely to have certain personality characteristics such as difficulty with assertion of angry feelings and a tendency to want the approval of others, in addition to more cosmetically disfiguring psoriasis. This personality constellation, superimposed on more disfiguring psoriasis, most likely makes these patients more vulnerable to the stresses resulting from the impact of psoriasis upon the quality of life. This psoriasis-related stress may, in turn, exacerbate the psoriasis in a circular manner. The clinician should carefully evaluate the degree to which psoriasis is affecting the patient's quality of life.

The mechanisms by which psychosocial stress may exacerbate psoriasis is currently a matter of speculation [30,51]. It is likely, however, that assertiveness training that helps the patient to express anger more effectively, and psychotherapy aimed at enhancing self-esteem, so that the patient is less interpersonally dependent, will improve the capacity of the high stress reactors to cope with the psoriasis-related daily stresses. Our study suggests that this should make the psoriasis less stress reactive. Group therapy and psoriasis self-help groups that aid the patients to deal with the daily stresses associated with psoriasis should be a part of all treatment programs for psoriasis. Finally, the dermatologist, who may be more concerned about extensive psoriasis on the trunk, rather than a small patch of psoriasis on the face or genitals, should be made sensitive to the psychosocial impact of psoriasis, so that psoriasis in "emotionally charged" body regions is treated more aggressively.

We wish to thank the staff of the Dermatology Inpatient and Daycare Units, University of Michigan for their collaboration, Ronald Kessler, Ph.D., Anita Delongis, Ph.D., Ernest H. Johnson, Ph.D., and Nancy
Genero, Ph.D., for their help, and the National Psoriasis Foundation for their support.

Ms. Gorr was a recipient of a fellowship from the University of Michigan Medical School student research program. The study was supported in part by the Babcock dermatologic endowment.

\section{References}

1. Christophers E, Krueger GG: Psoriasis. In Fitzpatrick TB, Eisen AZ, Wolff K, Freedberg IM, Austen KF (eds), Dermatology in General Medicine, 3rd ed. New York, McGraw-Hill, 1987, pp 461-491

2. Farber EM, Bright RD, Nall ML: Psoriasis, a questionnaire survey of 2144 patients. Arch Dermatol 98:248-259, 1968

3. Wittkower E: Psychological aspects of psoriasis. Lancet 1:566-569, 1946

4. Susskind W, McQuire RJ: The emotional factor in psoriasis. Scot Med J 4:503-507, 1959

5. Seville RH: Psoriasis and stress. I. Br J Dermatol 97:297-302, 1977

6. Fava GA, Perini GI, Santonastaso P, Fornasa CV: Life events and psychosocial distress in dermatologic disorders: Psoriasis, chronic urticaria and fungal infections. Br J Med Psychol 53:277-282, 1980

7. Baughman R, Sobel R: Psoriasis, stress and strain. Arch Dermatol 103:599-605, 1971

8. Shanon J: Psoriasis: Psychosomatic aspects. Psychother Psychosom 31:218-222, 1979

9. Medansky RS, Handler RM: Dermatopsychosomatics: Classifications, physiology, and therapeutic approaches. J Am Acad Dermatol 5:125-136, 1981

10. Koblenzer CS: Psychosomatic concepts in dermatology. Arch Dermatol 119:501-512, 1983

11. Epstein KN, Baughman RD: Role of psychosomatic influences in psoriasis. In Epstein E (ed), Controversies in Dermatology. Philadelphia, Saunders, 1984, pp 200-206

12. Ingram JT: The significance and management of psoriasis. Br Med J 2:823-828, 1954

13. Nyfors A, Lemholt K: Psoriasis in children. Br J Dermatol 92:437-442, 1975

14. Baker H: Psoriasis. In Rook A, Wilkinson DS, Ebling EJG, Champion RH, Burton JL (eds), Textbook of Dermatology, 4th ed. Oxford, Blackwell, 1986, pp 1469-1532

15. Nadelson T: Psychological understanding and management of cutaneous disease. In Fitzpatrick TB, Eisen AZ, Wolff K, Freedberg IM, Austen KF (eds), Dermatology in General Medicine, 3rd ed. New York, McGraw-Hill, 1987, pp 11-19

16. Gaston L, Lassonde M, Bernier-Buzzanga J, Hodgins S, Crombez J-G: Psoriasis and stress: A prospective study. J Am Acad Dermatol 17:82-86, 1987

17. Gilbert AR, Rodgers DA, Roenigk HH Jr: Personality evaluation in psoriasis. Cleve Clin Q 40:147-152, 1973

18. Payne RA, Rowland Payne CME, Marks R: Stress does not worsen psoriasis?-A control study of 32 patients. Clin Exp Dermatol 10:239-245, 1985

19. Shuster S: Stress and psoriasis. $\mathrm{Br} \mathrm{J}$ Dermatol 100:614-615, 1979 (letter) 
20. Baughman $R$, Sobel R: Emotional factors in psoriasis: Recent findings in Farber EM, Cox AJ (eds), Psoriasis. New York, Yorke, 1976, pp 180-188

21. Seville RH: Psoriasis and stress. II. Br J Dermatol 98:151-153, 1978

22. Benoit LJ, Harrell EH: Biofeedback and control of skin cell proliferation in psoriasis. Psychol Rep 46:831-839, 1980

23. Hughes HH, England R, Goldsmith DA: Biofeedback and psychotherapeutic treatment of psoriasis: A brief report. Psychol Rep 48:99-102, 1981

24. Frankel FH, Misch RC: Hypnosis in a case of longstanding psoriasis in a person with character problems. Int J Clin Exp Hypn 21:121-130, 1973

25. Waxman D: Behavior therapy of psoriasis-A hypnoanalytic and counterconditioning technique. Postgrad Med J 49:591-595, 1973

26. Leuteritz G, Shimshoni R: Psychotherapy and psoriasis_-Results at the dead sea. Z Hautkr 57:16121615,1982

27. Shafii M, Shafii SL: Exploratory psychotherapy in the treatment of psoriasis. Arch Gen Psychiatry 36:1242-1245, 1979

28. Coles RB, Ryan TJ: The psoriasis sufferer in the community. Br J Dermatol 93:111-113, 1975

29. Coles RB: Treatment of psoriasis in groups. Med World 103:127-135, 1965

30. Winchell SA, Watts RA: Relaxation therapies in the treatment of psoriasis and possible pathophysiologic mechanisms. J Am Acad Dermatol 18:101-104, 1988

31. Arnetz BB, Fjellner B, Eneroth P, Kallner A: Stress and psoriasis: Psychoendocrine and metabolic reactions in psoriatic patients during standardized stressor exposure. Psychosom Med 47:528-541, 1985

32. Baughman RD, Sobel R: Psoriasis, a measure of severity. Arch Dermatol 101:390-395, 1970

33. Stankler L: The effect of psoriasis on the sufferer. Clin Exp Dermatol 6:303-306, 1981

34. Gupta MA, Gupta AK, Kirkby S, Weiner HK, Mace TM, Schork NJ, Johnson E, Ellis CN, Voorhees JJ: Pruritus in psoriasis, a prospective study of some psychiatric and dermatologic correlates. Arch Dermatol 124:1052-1057, 1988

35. Holmes $T H$, Rahe $R H$ : The social readjustment rating scale. I Psychosom Res 11:213-218, 1967

36. Derogatis LR: SCL-90-R (revised) version, Manual-
1, clinical psychometrics research unit. Johns Hopkins University School of Medicine, Baltimore, 1977

37. Spielberger CD, Jacobs GA, Baker L: Preliminary manual for the state-trait personality inventory (STPI), Center for Research in Behavioral Medicine and Health Psychology. University of South Florida, Tampa, 1979

38. Carroll BJ, Feinberg M, Smouse PE, Rawson SG, Greden JF: The Carroll rating scale for depression. I. Development, reliability and validation. Br J Psychiatry 138:194-200, 1981

39. Feinberg M, Carroll BJ, Smouse PE, Rawson SG: The Carroll rating scale for depression. III. Comparison with other rating instruments. $\mathrm{Br} \mathrm{J}$ Psychiatry 138:205-209, 1981

40. Hirshfeld RMA, Klerman GL, Gough HG, Barrett J, Korchin SJ, Chodoff P: A measure of interpersonal dependency. J Pers Assess 41:610-618, 1977

41. Rosenberg M: Society and the Adolescent Self-Image. Princeton, NJ, Princeton University Press, 1965

42. Rosenberg M: Self-esteem and concern with public affairs. Public Opinion Q 26:201-211, 1962

43. Burton HJ, Kline SA, Lindsay RM, Heidenheim P: The effect of social networks, integration and support systems in determining quality of life for the ESRD patient. In Levy NB (ed), Psychonephrology IV. New York, Plenum, in press

44. Kaplan BH, Cassel JC, Gore S: Social support and health. Med Care 15 (Suppl):45-58, 1977

45. Cobb S: Social support as a moderator of life stress. Psychosom Med 38:300-314, 1976

46. Artz CP, Moncrief JA: The Treatment of Burns. Philadelphia, Saunders Company, 1969, pp 89-108

47. Johnson RA, Wichern DW: Applied Multivariate Statistical Analysis. Englewood Cliffs, NJ, PrenticeHall, 1955, pp 291-357, 461-530

48. Farber EM, Nall ML: The natural history of psoriasis in 5600 patients. Dermatologica 148:1-18, 1974

49. Delongis A, Coyne JC, Dakof G, Folkman S, Lazarus RS: Relationship of daily hassles, uplifts, and major life events to health status. Health Psychol 1:119136,1982

50. Dermatol Perspect 2, (2):6, 1986

51. Farber EM, Nickoloff BJ, Recht B: Stress, symmetry and psoriasis: Possible role of neuropeptides. J Am Acad Dermatol 14:305-311, 1986 